\title{
Produtividade de cultivares de amendoim no Oeste Paulista - safra 2020/2021
}

\author{
Submetido - 19 jun. 2021 \\ Aprovado - 31 jul. 2021 \\ Publicado - 30 set. 2021
}

http://dx.doi.org/10.52755/sas.v.2i(edesp1)120

\begin{abstract}
Discente curso de agronomia, isadora1bassanezi@gmail.com. Universidade do Oeste Paulista. E-mail:

Daniel Rodela Rodrigues (D) Mestrando em Produção Vegetal, Universidade do Oeste Paulista. E-mail: danielrodela@hotmail.com. Carlos Felipe dos Santos Cordeiro iD Doutorando em agricultura, Universidade Estadual Paulista, Campus Botucatu. E-mail: cordeirocfs@gmail.com.
\end{abstract}

Isadora Lyria de Alencar Bassanezi iD

Fábio Rafael Echer ${ }^{\text {DD }}$ Docente do curso de agronomia e Pós-graduação em agronomia, Universidade do Oeste Paulista. Email: fabioecher@unoeste.br.

\section{RESUMO}

O Estado de São Paulo é o principal produtor nacional de amendoim, e a produção está localizada principalmente na região de Jaboticabal, Tupã e Presidente Prudente. 0 objetivo desse estudo foi avaliar a produtividade de cultivares de amendoim em ambiente de solo arenoso no Oeste de São Paulo. O delineamento experimental foi feito em blocos ao acaso, com quatro repetições. Os tratamentos utilizados foram seis cultivares de amendoim: IAC 505, IAC 503, IAC OL3, IAC OL4, EC-98 e Granoleico. Foram avaliados os componentes de produção (número de vagens por planta, número de grãos por vagem e peso de 100 grãos), produtividade, rendimento de grãos e índice de colheita. As cultivares IAC 505 e Granoleico tiveram o maior número de vagens por $m^{-2}$. A cultivar EC-98 teve o maior peso de grãos $e$ índice de colheita. A cultivar IAC OL3 teve o maior rendimento de grãos. As cultivares IAC 505 e IAC OL3 tiveram as maiores produtividades.

Palavras-chave: Arachis hypogaea L.; Peso de grãos; Cultivo de sequeiro.

\section{Peanut cultivars yield in the west of São Paulo - 2020/2021 crop season}

\section{ABSTRACT}

The State of São Paulo is the main national producer of peanuts, and the production is located mainly in the region of Jaboticabal, Tupã and Presidente-Prudente. The aim of this study was to evaluate the yield of peanut cultivars in a sandy soil environment in the west of São Paulo. The experimental design was done in randomized blocks, with four replications. The treatments used were six peanut cultivars: IAC 505, IAC 503, IAC OL3, IAC OL4, EC-98 and Granoleico. Yield components (number of pods per plant, number of grains per pod and weight of 100 grains), yield, grain yield and harvest index were evaluated. Cultivars IAC 505 and Granoleico had the highest number of pods per $\mathrm{m}^{-2}$. Cultivar EC-98 had the highest grain weight and harvest index. Cultivar IAC OL3 had the highest grain yield. Cultivars IAC 505 and IAC OL3 had the highest yields.

Keywords: Arachis hypogaea L.; Grain weight; Rainfed cultivation.

Este é um trabalho de acesso aberto e distribuído sob os Termos da Creative Commons Attribution Attribution-NonCommercial-ShareAlike 4.0 International. 
Productividad de cultivares de maní en el occidente de São

Paulo - cosecha 2020/2021

\section{RESUMEN}

El Estado de São Paulo es el principal productor nacional de maní, y la producción se ubica principalmente en la región de Jaboticabal, Tupã y Presidente-Prudente. El objetivo de este estudio fue evaluar la productividad de cultivares de maní en un ambiente de suelo arenoso en el oeste de São Paulo. El diseño experimental se realizó en bloques al azar, con cuatro repeticiones. Los tratamientos utilizados fueron seis cultivares de maní: IAC 505, IAC 503, IAC OL3, IAC OL4, EC-98 y Granoleico. Se evaluaron los componentes de la producción (número de vainas por planta, número de granos por vaina y peso de 100 granos), rendimiento, rendimiento de grano e índice de cosecha. Los cultivares IAC 505 y Granoleico tuvieron el mayor número de vainas por m-2. El cultivar EC-98 tuvo el mayor índice de cosecha y peso de grano. El cultivar IAC OL3 tuvo el mayor rendimiento de grano. Los cultivares IAC 505 e IAC OL3 tuvieron Ios rendimientos más altos.

Palabras clave: Arachis hypogaea L.; Peso del grano; Cultivo de tierras secas.

\section{Introdução}

A escolha da cultivar é fundamental para obtenção de altas produtividades (Cordeiro et al., 2016), incluindo o amendoim. Isso é importante principalmente em ambientes de risco climático como no Oeste Paulista, nesses casos deve-se optar por cultivares mais tolerantes ao estresse hídrico. Isso porque o estresse hídrico é um dos principais limitantes da produção de amendoim em todo o mundo (Carrega et al., 2020; Furlan et al., 2020) e as perdas anuais podem chegar a aproximadamente 6 milhões de toneladas (Bhatnagar-Mathur et al., 2016). No Brasil $95 \%$ do amendoim é cultivado em no estado de São Paulo, cerca de $60 \%$ desse total é concentrado na região oeste do estado, onde predominam solos arenosos e a frequência de veranicos é alta o que pode limitar a produtividade das culturas (Cordeiro; Echer, 2019; Silva et al., 2020).

A resposta da planta ao estresse hídrico por seca inclui mudanças na condutância estomática, crescimento, acúmulo de osmólitos, e expressão de genes específicos (Furlan et. al., 2012). Na semeadura, a falta de água gera um atraso e diminuição da germinação (Carrega et al., 2020). Nos estádios vegetativos, a escassez de água causa o fechamento estomático, diminui a fotossíntese e a transpiração, reduz a área foliar e a absorção de energia luminosa (Haro et al., 2008). Afeta também diretamente o 
crescimento e o desenvolvimento das plantas, altura e comprimento dos ramos, além de reduzir a produção diária de flores (Chapman et al.,1993). Além desses fatores, o número de grãos também é afetado pelo estresse hídrico, devido a perda na produção de ginóforos, e o déficit hídrico durante o enchimento dos grãos afeta o peso dos grãos e a produtividade (Haro et. al., 2010). Dessa forma, avaliar quais cultivares melhor se adaptam às condições de clima e solo do oeste de São Paulo será sempre um dos principais fatores de produção.

Assim, o objetivo desse trabalho foi avaliar as cultivares de amendoim que melhor se adaptam nas condições edafoclimáticas de Regente Feijó, Oeste de São Paulo.

\section{Material e métodos}

O estudo foi conduzido em área comercial localizada em Regente

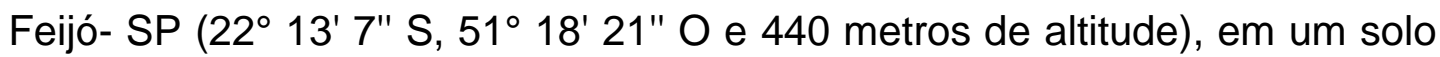
classificado como LATOSSOLO VERMELHO Distrófico, de textura arenosa. Os atributos do solo na camada de 0-20 cm eram: pH: 6,1, matéria orgânica: 16,2 $\mathrm{g} \mathrm{dm}^{-3}$, fósforo: 3,6 $\mathrm{mg} \mathrm{dm}^{-3}$, potássio, cálcio, magnésio e capacidade de troca de cátions: $0,9,15,0,10,2$ e $39,7 \mathrm{mmol}_{\mathrm{c}} \mathrm{dm}^{-3}$, respectivamente. $\mathrm{O}$ clima da região, segundo classificação de Köppen, é do tipo Aw, que significa clima mesotérmico com inverno seco.

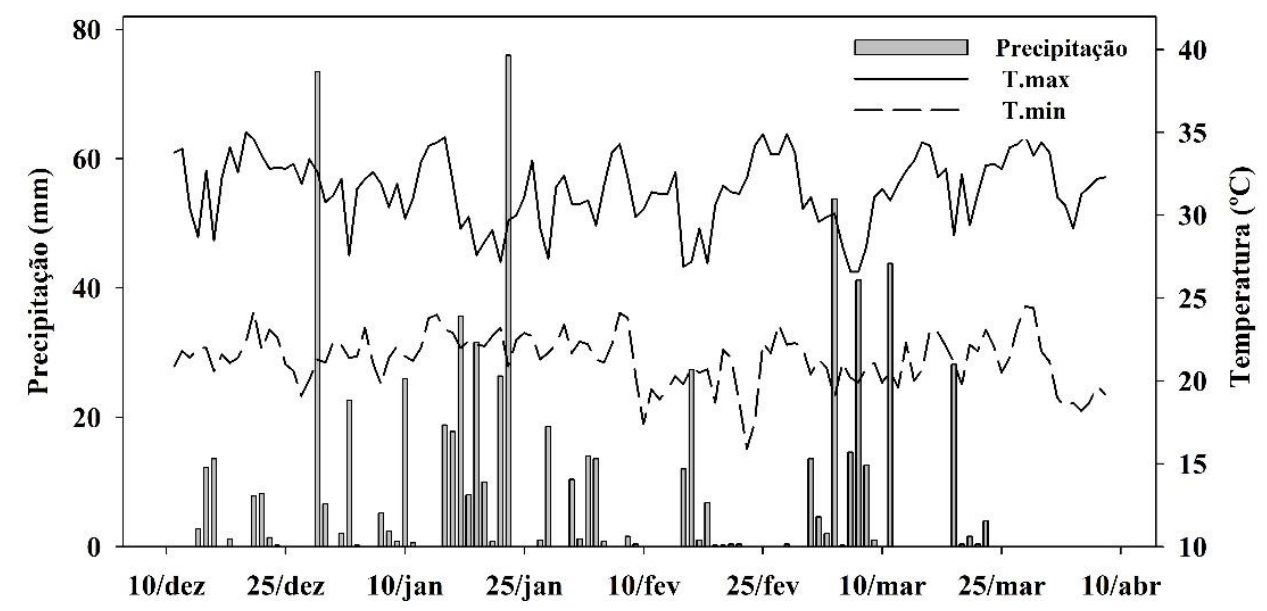

Figura 1. Precipitação, temperatura máxima e mínima, durante a condução do estudo. Regente Feijó-SP. 
O delineamento experimental foi em blocos ao caso, com quatro repetições. Os tratamentos utilizados foram seis cultivares de amendoim: IAC 505, IAC 503, IAC OL3, IAC OL4, EC-98 e Granoleico. As parcelas tiveram dimensões de 3,6 m (largura) (quatro linhas) x $5 \mathrm{~m}$ (comprimento).

Em setembro de 2020 foi realizada a calagem na dose de 1,3 Mg ha1. Em outubro foi realizado o preparo convencional do solo. No dia nove de dezembro de 2020 foi realizada a semeadura do amendoim, manualmente, com 20 sementes por metro e espaçamento de 0,90 m entre linhas (sistema de linha simples). A adubação de semeadura foi realizada com aplicação de 7,89 e $33 \mathrm{~kg} \mathrm{ha}^{-1}$ de $\mathrm{N}, \mathrm{P}_{2} \mathrm{O} 5$ e $\mathrm{K}_{2} \mathrm{O}$, respectivamente.

Por ocasião da maturidade dos frutos (114 dias após a emergência) foram coletadas todas as plantas de um metro de cada (no centro da parcela) uma das duas linhas centrais de cada unidade experimental para avaliação dos componentes de produção (número de grãos por vagem e peso de 100 grãos), produtividade, rendimento de grãos (matéria seca de grãos em relação a matéria seca da casca) e índice de colheita (matéria seca de amendoim em casca em relação a matéria seca da planta).

O estudo estatístico constou de análise de variância, e as médias dos tratamentos experimentais foram comparadas pelo teste de Tukey ao nível mínimo de $5 \%$ de probabilidade, utilizando-se software estatístico Sisvar.

\section{Resultados e discussão}

As cultivares IAC 505 e Granoleico tiveram maior número de vagens por metro quadrado que as demais. A cultivares IAC OL3, IAC 505 e IAC 503 apresentaram maior número de grãos por vagem que as demais cultivares, mas não foram diferentes entre si (Tabela 1). Em contrapartida, a cultivar EC 98 obteve grãos mais pesados e maior índice de colheita. $\mathrm{O}$ rendimento de grãos foi superior a $65 \%$ somente nas cultivares IAC OL3, Granoleico e IAC 505 (Tabela 1). 
Tabela 1. Número de vagens, número de grãos de vagem, peso de 100 grãos (g), rendimento (\%) e índice de colheita (IC) de cultivares de amendoim. Regente Feijó-SP, 2020/2021.

\begin{tabular}{lccccc}
\hline Cultivares & $\begin{array}{c}\text { Vagens } \\
\mathrm{m}^{-2}\end{array}$ & $\begin{array}{c}\text { Grãos } \\
\text { vagem }^{-1}\end{array}$ & $\begin{array}{c}\text { Peso de 100 grãos } \\
\mathrm{g}\end{array}$ & $\begin{array}{c}\text { Rendimento } \\
\%\end{array}$ & $\mathrm{IC}$ \\
\hline IAC 505 & $503,7 \mathrm{a}$ & $1,88 \mathrm{a}$ & $57,6 \mathrm{c}$ & $65,1 \mathrm{ab}$ & $59,8 \mathrm{~cd}$ \\
IAC 503 & $433,2 \mathrm{~b}$ & $1,89 \mathrm{a}$ & $55,0 \mathrm{c}$ & $63,4 \mathrm{bc}$ & $57,6 \mathrm{~d}$ \\
IAC OL3 & $404,9 \mathrm{~b}$ & $1,93 \mathrm{a}$ & $60,1 \mathrm{~b}$ & $67,7 \mathrm{a}$ & $62,9 \mathrm{bc}$ \\
IAC OL4 & $359,1 \mathrm{c}$ & $1,72 \mathrm{~b}$ & $60,7 \mathrm{~b}$ & $63,1 \mathrm{bc}$ & $66,2 \mathrm{~b}$ \\
EC 98 & $420,9 \mathrm{~b}$ & $1,65 \mathrm{~b}$ & $66,5 \mathrm{a}$ & $60,9 \mathrm{c}$ & $72,6 \mathrm{a}$ \\
Granoleico & $489,2 \mathrm{a}$ & $1,71 \mathrm{~b}$ & $61,0 \mathrm{~b}$ & $65,4 \mathrm{ab}$ & $65,9 \mathrm{~b}$ \\
CV\% & 8,3 & 5,5 & 5,3 & 3,4 & 5,4 \\
\hline
\end{tabular}

A produtividade de amendoim em casca foi maior nas cultivares IAC 505 e IAC OL3 (Figura 2). Isso devido provavelmente a melhor adaptação dessas cultivares no Oeste de São Paulo, sendo que para a cultivar IAC 505 o maior número de vagens e maior número de grãos por vagens foram determinantes para a maior produtividade e IAC OL3 o maior número de grãos por vagem. Contudo as produtividades foram superiores a $6000 \mathrm{~kg} \mathrm{ha}^{-}$ 1 (maior que a média nacional), produtividade considerada boa para a região, uma vez que a ocorrência da estiagem no final do ciclo limitou o ganho de peso de grãos.

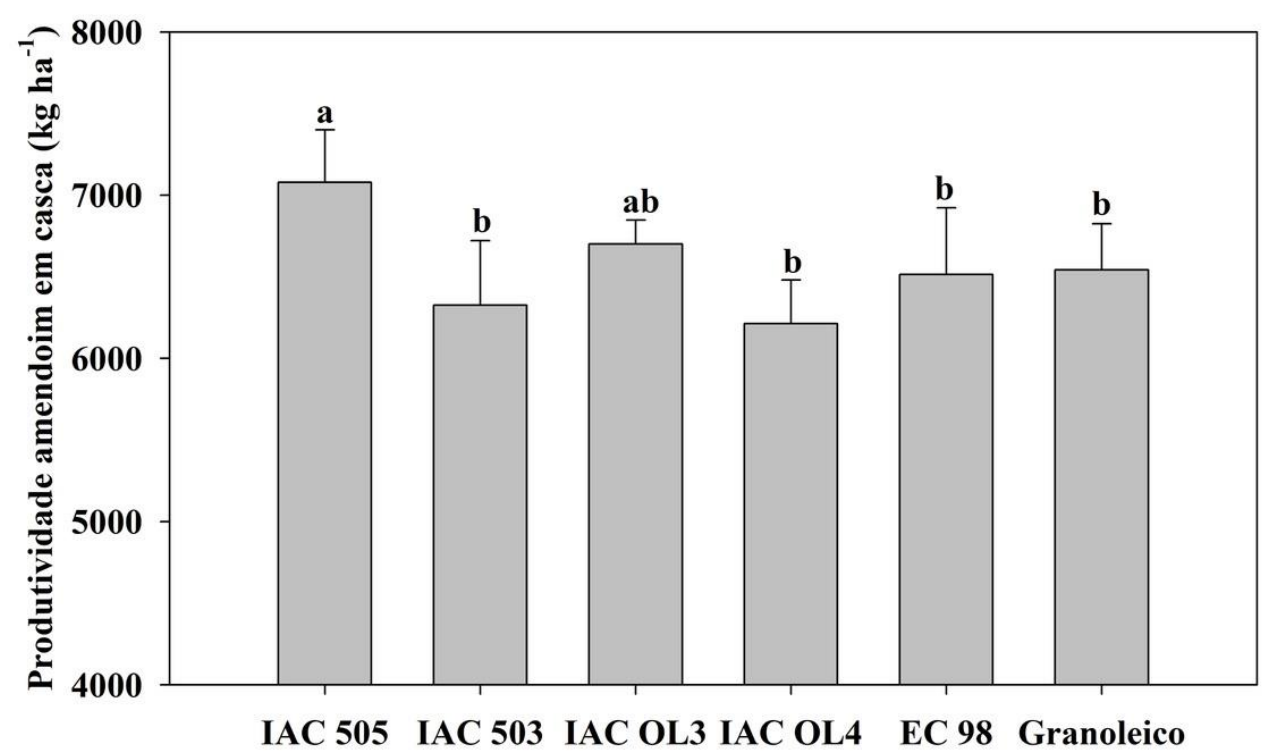

Figura 2. Produtividade de amendoim em casca de seis cultivares em Regente Feijó-SP, 2020/2021.

Em estudos desenvolvidos por Godoy et al., (2014) foi reportado ao alto potencial produtivo da cultivar IAC OL3, com produtividades próximas a 
$6000 \mathrm{~kg} \mathrm{ha}^{-1}$ similar ao nosso estudo. Dessa forma a cultivar IAC OL3 mesmo em condições de seca nesse estudo obteve alta produtividade, e entre as cultivares de ciclo precoce pode ser considerada a melhor opção para a região. Adicionalmente, em condições de seca, como verificado no nosso estudo no final do ciclo (Figura 1) a cultivar IAC 505 (ciclo tardio) foi a melhor opção em relação a cultivar IAC 503, assim como observado por Godoy et al. (2017).

Apesar de estudos anteriores com a cultivar EC-98, apresentar maior tolerância e à seca em relação a cultivar Granoleico (Furlan et al., 2020), em termos de produtividade à campo em condições de seca e solo arenoso não houve diferença de produtividade entre as duas cultivares (Figura 2). Novos estudos devem ser realizados na região considerando a época de semeadura e cultivares de diferentes ciclos de maturação.

\section{Conclusões}

As cultivares IAC 505 e IAC OL3 apresentaram melhor desempenho produtivo nas condições edafoclimáticas do Oeste de São Paulo na Safra 2020/21.

\section{Agradecimentos}

À Fundação de Amparo à Pesquisa de São Paulo (FAPESP) pela bolsa de iniciação científica a primeira autora (Processo no 2020/14480-8) e ao produtor rural Helder Lamberti pela disponibilidade de parceria para condução do ensaio em sua propriedade. 


\section{Referências}

Bhatnagar-Mathur, $\mathrm{P}$ et al. Transgenic peanut overexpressing the DREB1A transcription factor has higher yields under drought stress. Molecular Breeding, Dordrecht, v.33, p. 327-340, 2016.

Carrega, W. C. et al. Physiological responses of peanut genotypes to water déficit. Revista Brasileira De Ciências Ambientais, no 54, Jan 2020, p. 119-33, https://doi:10.5327/Z2176-947820190580.

Chapman, S. C.; Ludlow, M. M.; Blamey, F. P. C. Effect of drought durimg early reproductive development on the dynamics of yield development of cultivars of groundnut (Arachis hypogaea L.). Field Crops Research, Amsterdam, v.32, n.3-4, p. 227- 242, 1993)

Cordeiro, C.F.S., Echer, F.R. Interactive Effects of Nitrogen-Fixing Bacteria Inoculation and Nitrogen Fertilization on Soybean Yield in Unfavorable Edaphoclimatic Environments. Scientific Reports. 9, 15606. 2019. Disponível em: https://doi.org/10.1038/s41598-019-52131-7

Cordeiro, F.S.C. Perez, V.J., Echer, F.R. Produtividade de cultivares de algodão no Oeste Paulista. Colloquium Agrariae. v.12, p. 68-74. 2016. https://doi.org/10.5747/ca.2016.v12.nesp.000173

Furlan, A. L.et al. Physiological and Biochemical Responses to Drought Stress and Subsequent Rehydration in the Symbiotic Association PeanutBradyrhizobium sp. ISRN Agronomy. v. 2012. Jul 2012 http://doi:10.5402/2012/318083

Furlan, A.L., Bianucci, E. Castro, S., Dietz, K. J. Proline metabolic dynamics and implications in drought tolerance of peanut plants. Plant Science. Córdoba (Argentina). Jun 2020. https://doi.org/10.1016/i.plaphy.2020.04.010

Godoy, I. J. et al. IAC OL 3 and IAC OL 4: new Brazilian peanut cultivars with the high oleic trait. Cultivar Release. v. 14, feb 2014. Disponivel em: http://dx.doi.org/10.1590/1984-70332014 v14n3a30

Godoy, I. J. et al. IAC OL5 - New high oleic runner peanut cultivar. Cultivar Release. v. 17, feb 2017. Disponivel em: http://dx.doi.org/10.1590/1984- 70332017v17n3c45

Haro, R. J. et al. Seed yield determination of peanut crops under water déficit: Soild strength effects on pod set, the source-sink ratio and radiation use efficiency. Field Crops Research, Amsterdam, v.109, n. 13, p.24-33, 2008.

Haro, R. J. et. al. Water deficit and impaired pegging effects on peanut seed yield: links with water and photosynthetically active radiation use efficiencies. Crop and Pasture Science, Clayton, v.61, n. 5, p. 343-352, 2010. https://doi.org/10.1071/CP09234 
Silva, P.C.G., Tiritan, C.S., Echer, F.R., Cordeiro, C.F.S., Rebonatti, M.D., Santos. C.H. (2020). No-tillage and crop rotation increase crop yields and nitrogen stocks in sandy soils under agroclimatic risk. Field Crops

Research. 258. 107947. https://doi.org/10.1016/j.fcr.2020.107947 